OPEN ACCESS

Edited by:

Michael A. Yassa,

University of California, Irvine,

United States

Reviewed by:

Julien Rossignol,

Central Michigan University,

United States

Lakshmi Rajagopal,

Northwestern University,

United States

Yi Hu,

East China Normal University, China

${ }^{*}$ Correspondence:

Olga Matysiak

omatysiak1@swps.edu.p

Aneta Brzezicka

abrzezi2@swps.edu.pl

Received: 16 October 2018 Accepted: 13 May 2019

Published: 31 May 2019

Citation:

Matysiak $O$, Kroemeke $A$ and Brzezicka A (2019) Working Memory Capacity as a Predictor of Cognitive

Training Efficacy in the Elderly

Population.

Front. Aging Neurosci. 11:126. doi: 10.3389/fnagi.2019.00126

\section{Working Memory Capacity as a Predictor of Cognitive Training Efficacy in the Elderly Population}

\author{
Olga Matysiak ${ }^{1 *}$, Aleksandra Kroemeke ${ }^{1}$ and Aneta Brzezicka ${ }^{1,2 *}$ \\ ${ }^{1}$ Department of Psychology, SWPS University of Social Sciences and Humanities, Warsaw, Poland, ${ }^{2}$ Department \\ of Neurosurgery, Cedars-Sinai Medical Center, Los Angeles, CA, United States
}

Aging is associated with a decline in a wide range of cognitive functions and working memory (WM) deterioration is considered a main factor contributing to this. Therefore, any attempt to counteract WM decline seems to have a potential benefit for older adults. However, determination of whether such methods like WM trainings are effective is a subject of a serious debate in the literature. Despite a substantial number of training studies and several meta-analyses, there is no agreement on the matter of their effectiveness. The other important and still not fully explored issue is the impact of the preexisting level of intellectual functioning on the training's outcome. In our study we investigated the impact of WM training on variety of cognitive tasks performance among older adults and the impact of the initial WM capacity (WMC) on the training efficiency. 85 healthy older adults (55-81 years of age; 55 female, 30 males) received 5 weeks of training on adaptive dual $\mathrm{N}$-back task (experimental group) or memory quiz (active controls). Cognitive performance was assessed before and after intervention with measures of WM, memory updating, inhibition, attention shifting, short-term memory (STM) and reasoning. We found post-intervention group independent improvements across all cognitive tests except for inhibition and STM. With multi-level analysis individual learning curves were modeled, which enabled examining of the intra-individual change in training and inter-individual differences in intra-individual changes. We observed a systematic and positive, but relatively small, learning trend with time. Moderator analyses with demographic characteristics as moderators showed no additional effects on learning curves. Only initial WMC level was a significant moderator of training effectiveness. Older adults with initially lower WMC improved less and reached lower levels of performance, compared to the group with higher WMC. Overall, our findings are in accordance with the research suggesting that post-training gains are within reach of older adults. Our data provide evidence supporting the presence of transfer after $\mathrm{N}$-back training in older adults. More importantly, our findings suggest that it is more important to take into account an initial WMC level, rather than demographic characteristics when evaluating WM training in older adults.

Keywords: working memory training, cognitive training, working memory capacity, older adults, dual N-back 


\section{INTRODUCTION}

Advances in medicine and public health, in combination with rising standards of living, have lengthened the human lifespan. Increases in life expectancy, along with decreasing fertility rates, have led to the growth of a number of older adults in most populations. These days, a typical 60-year-old has many more years to live than a person of the same age 100 years ago (Office for National Statistics, 2017). This is unquestionably a positive change. However, there are also challenges associated with it. The most common effect concerns cognitive proficiency that is known to naturally decline with increasing age (Park and Payer, 2006; Salthouse, 2009; Harada et al., 2013). At the same time, new experiences and knowledge provide a potential for learning. This contrast between decline and learning is reflected in heterogeneous changes in cognitive performance that occur with age: while some of its aspects decline substantially, others may stay preserved. As previous empirical studies have indicated, age-related cognitive decline concerns especially fluid capacities (Salthouse, 2006; Hertzog et al., 2008; Lindenberger, 2014). Impairments are observable in measures of processing speed (Salthouse, 2009; Wahl et al., 2010), cognitive inhibition (e.g., Lustig et al., 2007; Rey-Mermet and Gade, 2018), processes of shifting (between tasks or mental sets) (meta-analysis: Wasylyshyn et al., 2011) and working memory (WM) (Kramer et al., 1999; Park et al., 2002; Klencklen et al., 2017). According to a definition by Miyake et al. (2000), abovementioned functions constitute executive functions (EF) and are crucial for cognitively demanding day-to-day activities such as planning, reasoning, problem-solving, reading comprehension, and more general aspects of fluid intelligence (Cowan, 2010; Thompson et al., 2013). Therefore, all attempts to counteract the decline in EF are potentially beneficial for older adults and especially, cognitive training programs. WM seems to be a reasonable target for a cognitive training, given that it is perceived as a central component of general cognition and is inherently engaged in all higher-level cognitive activities. WM is referred to a moment-to-moment cognitive processing and temporary information storage (Logie et al., 2015). Studies have shown that the capacity of WM could be an indicator of performance in several other cognitive tasks: from simple attentional tasks (Kane et al., 2001; Bleckley et al., 2003; Fukuda and Vogel, 2009) to tasks requiring more compound capabilities, such as reading comprehension (Daneman and Carpenter, 1980), reasoning and problem solving (Kyllonen and Christal, 1990; Fry and Hale, 1996; Barrouillet and Lecas, 1999; Engle et al., 1999), as well as executive functioning in everyday life (Kane et al., 2007; Nagel and Lindenberger, 2015). Accordingly, one could expect that training-based increases in WM efficiency will be reflected as improvements in several other functions.

However, the effectiveness of WM training has been an ambiguous and passionately debated issue lately, especially the aspect of post-training growth in untrained abilities. A number of meta-analyses and reviews have addressed this matter (for meta-analysis see: Melby-Lervåg and Hulme, 2013; Karbach and Verhaeghen, 2014; Au et al., 2015; Schwaighofer et al., 2015; Melby-Lervåg et al., 2016; Soveri et al., 2017; for reviews see: Lövdén et al., 2010; Shipstead et al., 2010, 2012; Melby-Lervåg and Hulme, 2013; Shinaver et al., 2014; Au et al., 2016; Dougherty et al., 2016; Weicker et al., 2016). Initial enthusiasm about WM training effectiveness on fluid intelligence evoked by the results from Jaeggi et al. (2008); (see also: Lövdén et al., 2010), waned. In 2013 other researchers argued that "...there was no convincing evidence of the generalization of WM training to other skills" (Melby-Lervåg and Hulme, 2013 , p. 270). Shinaver et al. (2014) responded with the metaanalysis showing highly significant effects of WM training on advancing verbal WM and visuospatial WM and thus confirming the existence of the near transfer. In 2015 another team (Au et al., 2015) reaffirmed those findings by showing a significant increase in fluid intelligence as a result of WM training. This conclusion was in line with results presented by others (Karbach and Verhaeghen, 2014; Schwaighofer et al., 2015). In 2016 Melby-Lervåg and Hulme, previously skeptical, presented a meta-analysis with positive post-training effects (Melby-Lervåg et al., 2016). Following training, there were reliable improvements in performance on verbal and non-verbal working-memory measures identical or similar to the trained tasks. However, in terms of the far transfer, there was no convincing evidence of improvements, especially when workingmemory training was compared to an active-control condition. Also, Weicker et al. (2016) found small transfer effects to cognitive control and attention, but no transfer to long-term memory or reading comprehension. McCabe et al. (2016) went further and concluded their review with the idea that WM trainings, in the form that they are currently implemented, shall not be effective. However, the latest reports and meta-analysis are more hopeful. Soveri et al. (2017) observed medium-sized transfer effects to untrained N-back tasks and rather small effects for other WM tasks. However, overall pre-post training gains are medium sized and significantly higher than in control groups (Piryaei and Ashkzari, 2017).

Working memory training studies examined the role of age in explaining the benefits of training mostly by comparing young and older adults (see Borella and De Ribaupierre, 2014; for a review). Likewise, these results are ambiguous. Part of the studies reported larger enhancements in younger than in older adults (e.g., Dahlin et al., 2008; Schmiedek et al., 2010; Dorbath et al., 2011; Brehmer et al., 2012; Heinzel et al., 2014; Zinke et al., 2014). Other suggested that training gains are comparable (Li et al., 2008; Richmond et al., 2011; Bürki et al., 2014; von Bastian and Oberauer, 2014; Zając-Lamparska and Trempała, 2016). As showed by Borella et al. (2017), if near or far transfer effects existed, the studies found either no differences between the two age groups, or larger effects in young adults than in older adults. Regarding the long-term effects, only two reviewed articles noted similar training improvements for both young as well as older participants, and only one found near and far transfer effects. However, larger long-term training-specific gains for young adults, and comparable long-term near transfer effects were also documented (Li et al., 2008). Among the studies focusing only on older adults, the ones that found significant training gains and transfer effects, were especially those involving young-old participants ( $<74$ years old). Studies that included 
old-old participants (75-87 years old) or those that considered a broad age range reported mixed findings in terms of specific and transfer training gains. Likewise, according to the meta-analysis by Karbach and Verhaeghen (2014), cognitive interventions resulting in positive effects are those referring to near transfer. Far transfer observed in pre-to-post-training gains was significantly higher when improvements were compared to passive control group. Nonetheless, when analyzing group differences only at post-test level, profits were significantly bigger regardless of type of control group.

There have been mixed reports on the matter of the efficacy of WM training in aging, what makes it necessary to identify factors that are involved in modulating training benefits. We can specify the numerous elements that are believed to predict the benefits of memory training (e.g., Verhaeghen and Marcoen, 1996) and may also play a role as modulators of WM training outcomes (Bürki et al., 2014). The most prominent among them seems to be general cognitive ability and baseline cognitive resources. In an aforementioned work, Borella et al. (2017) showed that participants who had a higher initial cognitive performance and/or were younger were more likely to improve after the training. Interestingly, for more passive tasks (i.e., the Forward Digit Span - short term memory task) they observed a compensation effect: older subjects with lower initial vocabulary scores and weaker WM performance benefited more from the WM training. The same pattern was observed in the test similar to the trained task: participants with poorer achievements in a task based on crystallized intelligence - determined with the vocabulary test, benefited more than those with higher vocabulary scores. According to the authors, such pattern of results suggests that knowledge can counterbalance age-related decline (e.g., Baltes, 1987). These findings are considered an evidence for the compensation effect, which states that lower functioning individuals will have greater training benefits than high-functioning individuals, because they have higher learning potential (Olazarán et al., 2004). This was also confirmed in other studies (Ranganath et al., 2011; Zinke et al., 2012, 2014; Bürki et al., 2014). At the same time, the contrary hypothesis: so-called Matthew effect, exists. This phenomenon, popular in educational research (e.g., Bakermans-Kranenburg et al., 2005), refers to the observation that individuals with high initial ability are more likely to improve their skills to an even greater extent.

Taken together, there are solid foundations to believe that baseline cognitive resources could be crucial for WM training gains. It is, however, surprising how little reports have been published on this topic (e.g., Bürki et al., 2014; Foster et al., 2017). In fact, even large individual differences in initial cognitive resources, especially across older adults, are often neglected in the analyses of intervention research (Kliegel and Bürki, 2012). For this reason, this study investigated the influence of initial cognitive resources on WM training's effectiveness in healthy older adults. We verified the possibility that demographic factors such as age, gender, education level or occupational activity of older adults could modify the training outcome. We compared a computerized, home-based dual N-back training program (experimental group) and an active control training based on a memory quiz (active control group). Including an active comparison group, instead of passive one, allowed for controlling every other element, except for the task used in the training (training content). The quiz task served as an active comparison since no impact of a semantic memory training (that refers to general knowledge of facts, ideas, and concepts) on WM has been found so far (see e.g., Li et al., 2016).

\section{MATERIALS AND METHODS}

\section{Participants}

A total of 85 volunteers (55 female and 30 male) who matched inclusion criteria, aged 60 years and older (mostly from Warsaw, Poland) were recruited from Internet advertisements, Universities of the Third Age and social events for elderlies. Exclusion criteria were: history of brain trauma, use of medication known to affect cognition, progressive neurological diseases or severe hear or eyesight deficits. Participants were additionally screened for cognitive impairments [people with scores below 27 on the Mini-Mental State Examination (Folstein et al., 1975) were excluded from participation in the study]. 83 participants attended pre- and post-training tests. All seniors completed 25 training sessions although, as a result of technical problems, data from one participant was not recorded at all, same as information from 2 training sessions from another participant. For two seniors OSPAN task results from first measurement were improperly saved, therefore were excluded from analyses. Applicants were randomly divided into two training groups.

\section{Procedure}

This study was carried out in accordance with the recommendations of the SWPS University of Social Sciences and Humanities Ethics Committee with written informed consent from all participants. All participants gave written informed consent in accordance with the Declaration of Helsinki. The research consisted of three steps (sessions): (1) Pre-training measurement of cognitive functions, (2) Training sessions, and (3) Post-training evaluation of cognitive performance (within a week following the last training) (Figure 1). Experimenters were present in all pre- and post-training meetings that took place in the laboratories of the SWPS University in Warsaw.

Working memory training was based on adaptive version of the dual N-back task. Active control group trained on semantic memory with the authorial Quiz Task. None of the training tasks were administered during evaluation. However, N-back tasks were discussed in detail with each participant, to ascertain that task objectives are comprehensible. Both training groups attended exactly 25 on-line training sessions spanning over 5 weeks. There were no restrictions concerning where or when practice should take place but the volunteers were obligated to accomplish the minimum of five training sessions per week and no more than one session per day. Subjects also needed to attend all of the sessions to be compensated and included in the analysis. The total compensation for each participant completing the experiment was 150 PLN $(\sim \$ 40)$. Although participants were asked to not engage in other forms of "brain training" during the study period, we were unable to control for such potential contamination. 


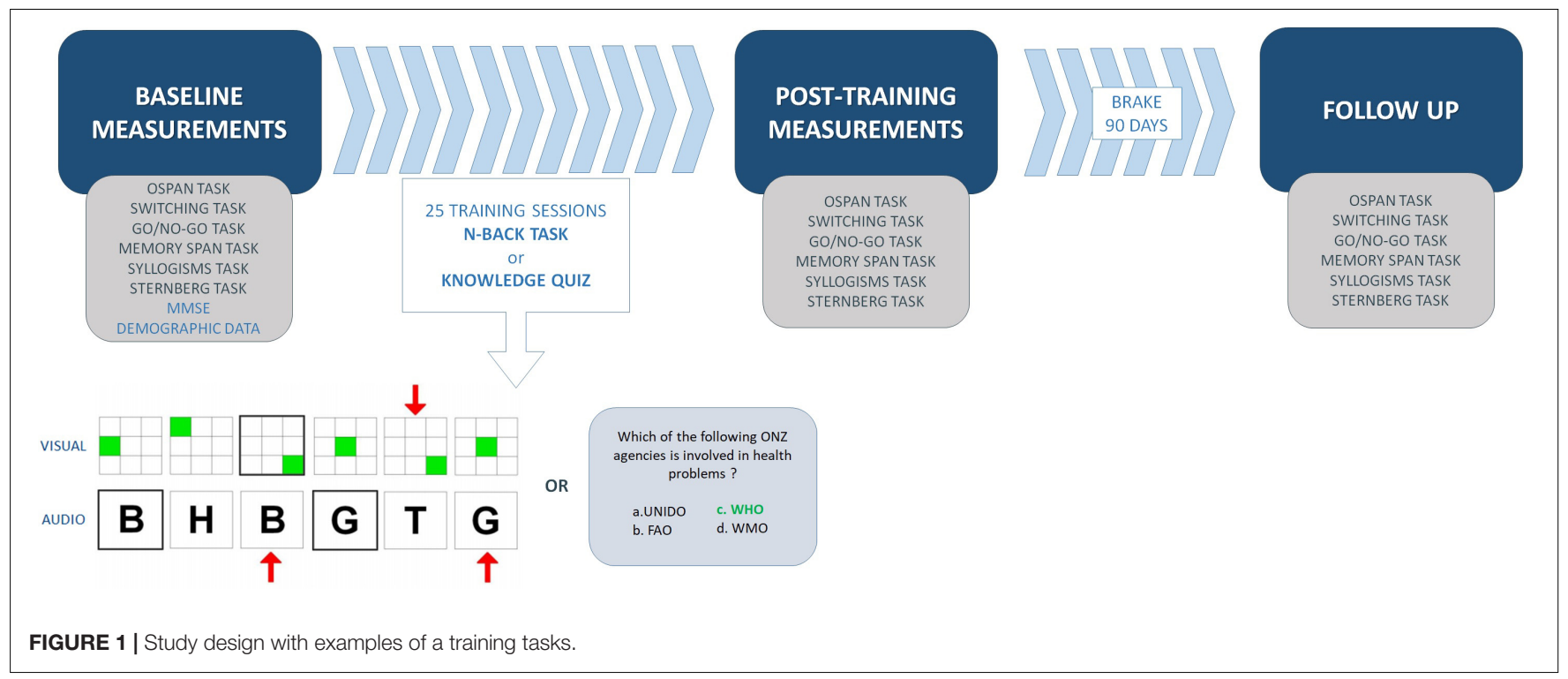

\section{Training Programs}

\section{Training Task 1 - Dual N-Back Task}

An adaptive dual N-back task is a complex WM training program that simultaneously recruits auditory and visual attention, maintenance, and updating processes introduced by Jaeggi et al. (2008) One dual N-back session consisted of 15 rounds of 20 $+\mathrm{N}$ trials. Prior to the start of the actual task the participants were briefly instructed on the task at level $N=2$. The visual stimuli were green squares presented in one of nine locations in a $3 \times 3$ matrix. Alphabet letters served as auditory stimuli. Each trial consisted of a 500-ms item presentation followed by a $2500-\mathrm{ms}$ interval, during which the participants were supposed to respond. Volunteers were instructed to answer with a keyboard whenever the current stimuli matched the target stimuli presented $\mathrm{N}$ trials back. The current stimuli could match the target visual (response with left hand) or auditory stimulus (response with right hand) or both (response with both hands simultaneously). The N-back level was fixed at $N=2$ for the first block, after which the $\mathrm{N}$ level for the current block was determined by the correctness of answers in the previous block. If accuracy fell below 85\%, difficulty would not increase. Participants were informed of the N-back level before the start of each block. Reaction times (RTs) and accuracy (ACC) measures were obtained for each trial.

\section{Training Task 2 - Memory Quiz}

The active control group task comprised of 135 questions, which engage semantic memory. The questions were based on the material collected from the Internet. The training regime consisted of 25 sessions with 15 random questions each. The trainee was to answer the questions presented one after another. There was no time limit to read the question but after selecting the "answer" button the participant had to choose one of the four given possibilities within $40 \mathrm{~s}$. The feedback about correctness was provided. Each session included 5 questions presented in the previous test and 10 new.

\section{Outcome Measures}

Baseline and post-training neuropsychological assessment involved cognitive tests estimating WM, attention switching, processing speed and fluid intelligence. Measures were chosen on the basis of their use in previous investigations of WM training, their ability to reliably measure the cognitive domains of interest, and their sensitivity to age-related differences in cognitive performance. Each measure is described in detail below.

\section{Operation SPAN Task}

We used computerized version of original OSPAN Task (Turner and Engle, 1989). During each trial of this complex span task participants had to validate the results of simple equations and memorize a set of letters (F, H, J, K, L, N, P, Q, $\mathrm{R}, \mathrm{S}, \mathrm{T}, \mathrm{Y}$ ) at the same time. There were three practice sections: (1) Letter span: a group of letters appeared on the screen one by one, for $1000 \mathrm{~ms}$ each (in all experimental conditions). Participants were required to recall and choose the letters from the presented matrix, in the same order as they were presented. There was no time limit for this part. (2) Mathematical equation: Participants were instructed to calculate the results of the operations displayed on the screen (e.g., $3 * 5-1=$ ?) as quickly as possible and decide whether the presented on the next screen answer is correct (e.g., 16 - True/False?). During this section the program estimated individual time for participants required to solve the calculations. This time (plus $2.5 \mathrm{SD}$ ) was then used as the maximum time allowed for the mathematical portion in the main part of the task. (3) Mixed practice: Participants performed both subtasks, just as they would do in the real block of the attempts. Because of the dual-task character, complex span tasks put severe demands on EFs: apart from the updating of the WM content, subjects have to shift between the two subtasks and inhibit currently irrelevant information (Conway et al., 2002). A main task was identical to mixed practice section. This task is highly correlated with other measures of 
WM and fluid intelligence (Unsworth et al., 2005). Furthermore, it requires immediate attention, manipulation of information within immediate memory span and information updating. Therefore, OSPAN's results may be reckoned as a complex measure of a cognitive reserve based on the WM capacity.

\section{Syllogisms Task}

Participants solved a computerized version of the linear-order reasoning paradigm - Syllogisms Task. This task consisted of set of premises that constituted logical chain of relations, and five questions about those relations. Three pairs of relations were studied in separate trials, each premise contained a pair of letters and information about a relationship between them e.g., "A > B," "B > C," and "C > D." An integrated mental model representation (Johnson-Laird, 1983) of such a set of pairs would always be in the linear order "A $>\mathrm{B}>\mathrm{C}>\mathrm{D}$." There were two phases of the task - learning and testing. In the learning phase of the reasoning condition participants had to integrate presented information from three premises, where the first two were not related until the third premise appeared (A $>$ B was followed by $\mathrm{C}>\mathrm{D}$ and in the end by $\mathrm{B}>\mathrm{C}$ ). Immediately after presentation of the three pairs, we tested participants on all possible pairs within the order, i.e., $\mathrm{AB}, \mathrm{BC}$, $\mathrm{CD}$ (adjacent pairs, exactly the same as those that had been seen in the learning phase), AC, BD (two-step relations, not seen before and requiring integration of information), and $\mathrm{AD}$ (end point relation, not seen before and requiring integration of information), by prompting participants with statements in either a correct (e.g., "A > D") or false format (e.g., "D > A") and asking them for a speeded verification. We used capital letters as stimuli in all tasks instead of whole sentences in order to avoid linguistic connotations, and the symbol "> " was additionally presented to indicate the relation between elements. The arrangement of the letters was randomized in order to minimize possible interference induced by implied alphabetical ordering of letters. In the testing phase participants had to decide whether the questions about relations between letters were true (right button) or false (left button). In the easy condition premises were displayed one after the other (the subsequent premises had common element: e.g., $\mathrm{B}>\mathrm{V} ; \mathrm{V}>\mathrm{M} ; \mathrm{M}>\mathrm{A}$ ) in the difficult condition order of premises presentation was mixed (e.g., $\mathrm{B}>\mathrm{V} ; \mathrm{M}>\mathrm{A} ; \mathrm{V}>\mathrm{M}$ ). Questions about adjacent pairs probed memory and questions about two-step relations and endpoint relations asked about information integration ability. The accuracy and response time (RT) for each question in both conditions were measured.

\section{Memory SPAN Task}

A digit-span task was used as a measure of WM storage capacity. During each trial of this task participants were presented with a series of letters, which elongated with each attempt. The stimuli were presented in the center of the screen for $1,500 \mathrm{~ms}$, followed by a $500-\mathrm{ms}$ interval. At the end of each trial, the participants were asked to recall between 3 and 6 last elements (maximum length of the series were 9). The participant's span is the longest number of sequential digits that can accurately be remembered. Accuracy of recollection for each span was calculated.

\section{Sternberg's Task}

Participants performed a computerized version of Sternberg's paradigm (Sternberg, 1966). Each trial consisted of 2 to 5 white digits presented on a black screen in a sequence $(1200 \mathrm{~ms}$ each). After maintenance period (2500 ms after the last digit) a yellow digit (target) appeared and participants had to indicate whether displayed sequence contained this digit or not (by pressing the adequate button). Task sessions were divided into equally distributed positive ("in" - probe present in the memory sequence) and negative ("out" - probe not present in the memory sequence) attempts. There were 120 experimental trials in total, preceded by 15 trials of the training. Accuracy of answers was measured.

\section{Attention Switching Task}

We reused procedure proposed by Dobrowolski et al. (2015), created on the basis of the tasks used by Colzato et al. (2013), with target stimuli adapted from Huizinga et al. (2006). Participants reacted as fast as possible to two kinds of requirements of the task. They had to decide if the figure is a square or a rectangle (condition 1 global) or if the figure consists of squares or rectangles (condition 2 - local), depending on the presented cue. Global figures were comprised of smaller, local figures. Two training blocks were administered (each of 50 trials) with constant instruction across all trials. Answer was given by pressing "left button" for squares and "right button" for rectangles. Experimental block consisted of 160 trials in which participants switched between global and local. The measure of switch cost, based on differences in reaction times for conditions, was calculated.

\section{Go/No-Go Task}

The go/no-go is a cognitive task aimed at determining the ability of an individual to inhibit a response deemed inappropriate. Participants had to respond with a keyboard as fast as possible to the target stimulus (letter " $\mathrm{X}$ ") presented in the center of the screen, and to suppress the reaction for any other letter. The task consisted of two conditions based on ratio of go/nogo trials: easy- where ratio was 70/30, difficult - with ratio equal 50/50 (when half of the target letters came after target letter and the half came after any other letter). The trials were displayed on a white screen and composed of a $250 \mathrm{~ms}$ fixation point (white + ), the stimulus presentation (a letter) for $1250 \mathrm{~ms}$ and a fixed inter-stimulus interval of $2000 \mathrm{~ms}$. We considered the go/no-go task as a measure of cognitive inhibition efficiency.

\section{Statistical Analyses}

All analyses were conducted using IBM SPSS Statistical Package for the Social Sciences (SPSS) version 24 and using Matlab custom scripts. For tasks that controlled the reaction time (Sternberg's, Switching, Go/no go, OSPAN tasks) outlying trials (exceeding cut-off of 2.5 standard deviations, individually calculated for each participant) were removed. A significance level of $p<0.05$ was adopted for all conducted tests and post hoc comparisons. All post hoc between-groups comparisons 
were Bonferroni corrected. Repeated measures multivariate analysis of variance (RM-MANOVA) was used to test for differences in training groups (N-back training, Quiz training) over time (pre-, post-training) across the dependent variables (outcome measures).

In order to find a more refined method to observe learning process, i.e., the unique effects of performance in the 1st training session and cumulative change in training improvements over time, we decided to conduct multilevel modeling (MLM). MLM provides the best parameter estimates while accommodating the hierarchical structure of the data: repeated measurements (level 1) nested within participants (level 2) (Bolger and Laurenceau, 2013). The MLM analysis dataset consisted of 42 (participants) $\times 25$ (sessions) $=1,050$ observations. Both fixed (the regression intercept and slope for the average person) and random effects (between-subject variability around the average) were examined. In Model 1, the change in N-back task scores over time was modeled represented by the number of a training session as a predictor (time). To test predicting and moderating effects of demographics (age, sex, education level, occupational activity) as well as the influence of a baseline OSPAN score (between-person predictors - level 2) on withinsubject variation (level 1) in N-back training additional models (2 to 6) were calculated. To avoid multicollinearity, all predictors were tested separately. Initial OSPAN score was categorized and two groups were created: (1) group with higher than mean scores (high initial OSPAN), (2) group with average and lower than average scores (low initial OSPAN). Age was grandmean centered and dummy-codes were created for categorical demographic variables. In all models, a quadratic effect for the slope (besides linear one) was tested and subsequently removed because its fixed effects and variance components were not significant. The time variable was centered at 1 st day of the training. The restricted maximum likelihood (REML) was used as the estimator. Goodness of fit for the models was based on -2 Restricted log likelihood ratio (-2LL) and the Akaike Information Criterion (AIC). The first-order autoregressive $[\mathrm{AR}(1)]$ covariance structure was used for the models, given the common proximal autocorrelation in the daily data (Kwok et al., 2008).

\section{RESULTS}

\section{Participants Characteristics}

There were no group differences in the demographic data, but we found variance between groups in the baseline measure of general cognitive functioning - OSPAN task. Table 1 presents participants' characteristics.

\section{Training Tasks Results}

Training results were analyzed in the N-back group only as the quiz group did not undergo a cognitive training and executed tasks of equal difficulty through the whole length of the study. Training progress in the WM training group was based on maximum N-back level achieved in each of 25 training sessions. All participants started at level $N=2$ and
TABLE 1 | Participants characteristics at baseline.

\begin{tabular}{lcccc}
\hline & N-back group & Quiz group & \multicolumn{2}{c}{ Statistics } \\
\cline { 3 - 5 } & & & Test & p-Value \\
\hline$N$ & 42 & 42 & $X^{2}(1)=0.12$ & 0.914 \\
Age & $M=65.9$ & $M=67.5$ & $t(82)=2.342$ & 0.199 \\
Sex (female/male) & $28 / 15$ & $27 / 15$ & $X^{2}(1)=0.006$ & 0.936 \\
$\begin{array}{l}\text { Education } \\
\text { (higher/secondary) }\end{array}$ & $27 / 16$ & $21 / 21$ & $X^{2}(1)=1.414$ & 0.234 \\
$\begin{array}{l}\text { Occupational } \\
\text { activity }\end{array}$ & $13 / 29$ & $10 / 32$ & $X^{2}(1)=539$ & 0.463 \\
$\begin{array}{l}\text { (active/retired) } \\
\begin{array}{l}\text { OSPAN scores } \\
\text { (high/low) }\end{array}\end{array}$ & & & & \\
$\begin{array}{l}\text { OSPAN scores } \\
\text { [absolute score] }\end{array}$ & $M=15.31$ & $M=9.07$ & $t(80)=0.322$ & 0.233 \\
\hline
\end{tabular}

Group (N-back - training group; Quiz - active control group) differences at baseline. Parenthesis () for categorial variables, [] for continuous data. *Statistical significance: $p<0.05$.

could increase this number by good execution ( $80 \%$ of accuracy in the block) of the task or have it set to the $N=1$ level because of poor performance in task (below 65\% of accuracy in the task). Throughout training, $21.4 \%$ of the volunteers never surpassed entering level, other $28.6 \%$ reached maximum 3-back, and almost half of the group managed to attempt 4back $(47.6 \%)$. Only one participant reached 5-back. The mean maximal N-back level achieved through the whole training was $3.31(S D=0.14)$, and on the last day of training - 2.9 $(S D=0.15)$. The difference in average $\mathrm{N}$-back level achieved from the first to last day of training was statistically significant, $t(40)=5.89, p<0.001$.

Results of MLM indicated that the initial N-back level was 2.16 on a $1+\infty$ scale and showed a 0.03 unit increase over 25 days of training (see MODEL 1, Figure 2 and Table 2). In addition, all random effects were significant, pointing to the between-person variability in intercept, slope, and positive correlation between max n-level achieved in the first time of a training and upswing in the task results over time.

\section{Predictors of a Training Effectiveness}

The results of MLM for models 2-6 (Table 2) revealed that none of demographic variables was predictive neither of the initial level of max N-back nor of its change over time. Only baseline OSPAN performance turned out to be a significant predictor of the N-back result at the first day of training and moderator of the whole training course. Both groups, with high versus low OSPAN scores, showed an initial N-level of approximately 2.00 units on a $1+\infty$ scale (low OSPAN $=1.93$; high OSPAN $=1.93$ $+0.38=2.31$ ). After training, the participants with low initial OSPAN scores showed a 0.01 unit increase in $\mathrm{N}$-back level, whereas the participants with the high initial OSPAN scores showed a $0.01+0.03=0.04$ unit increase in N-back training. The initial performance of the OSPAN task clearly affects the trajectory of improvement during the training: people with a higher initial OSPAN score have 


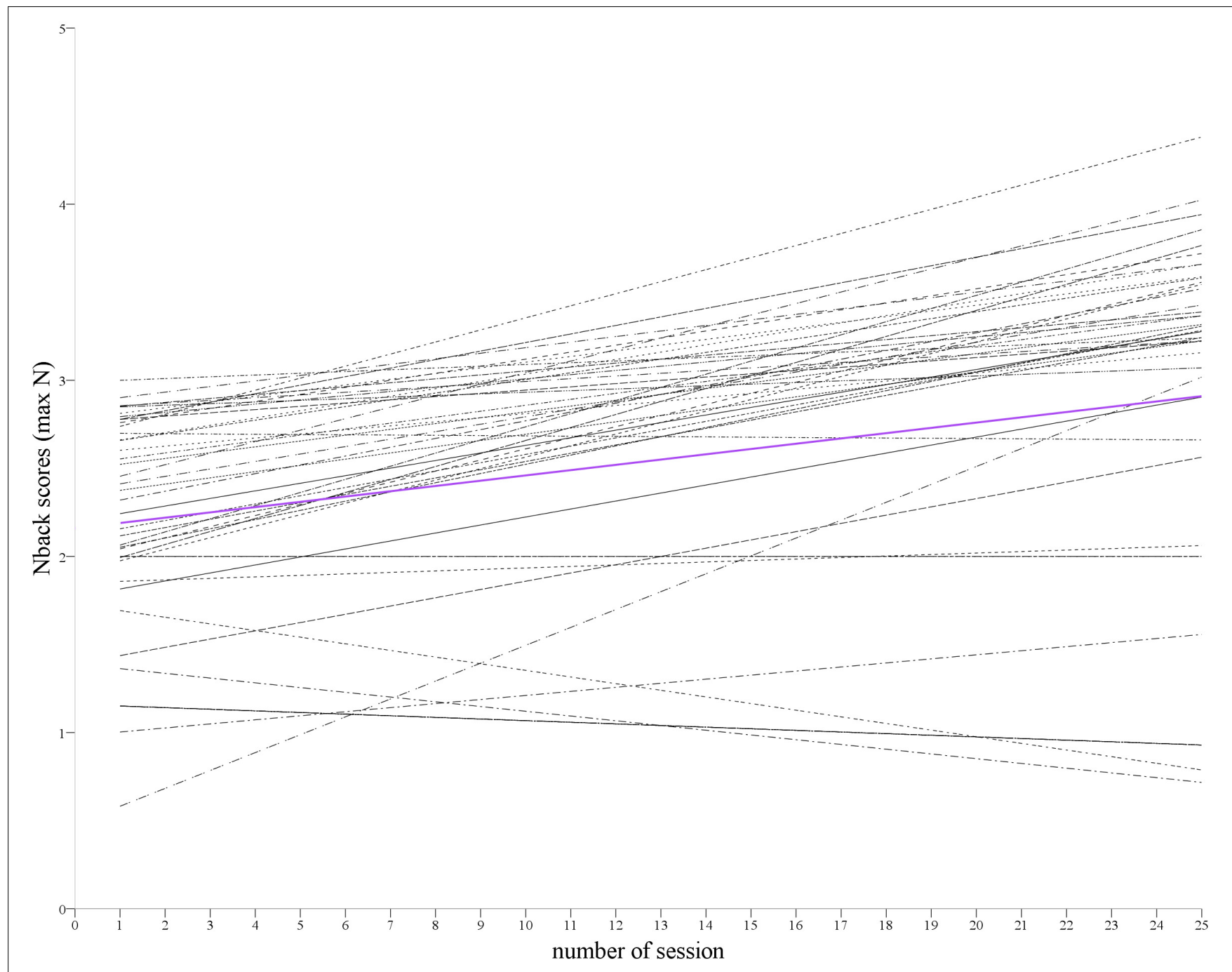

FIGURE 2 | N-back training effectiveness. Change in training task scores (N-back) over time (training sessions) estimated for each participant (black lines).

significantly higher $\mathrm{N}$-level achievement in the 1 st session and a steeper learning curve in training $(p<0.001)$, which is presented in Figure 3.

\section{OUTCOME MEASURES RESULTS}

To determine whether baseline cognitive performance was comparable across training groups, we conducted a MANOVA with all the pretest measures as the dependent variables and the training group as the between-subjects factor. The main effect of the group was not significant, $F(8,71)=1.815, p=0.88, \eta_{\mathrm{p}}^{2}=0.17$. In addition, almost all of the Bonferroni corrected post hoc between-groups comparisons for outcome measures were non-significant. We noted pre-training group discrepancy in one task. The $\mathrm{N}$-back group showed better baseline performance in the OSPAN task than the active control group (Mdiff $=6.79$, $\left.p=0.007, \eta_{\mathrm{p}}^{2}=0.09\right)$.
Transfer effects were analyzed for each outcome results for both training groups over time (pre-, post-training) with RMMANOVA using tasks' performance as dependent variables, and training group and measurement points (pre- versus posttraining) as independent variables. Table 3 presents results of this analysis.

Repeated measures multivariate analysis of variance revealed post-training improvement in OSPAN performance (a strong tendency toward statistical significance: $p=0.06$ ). However the initial disproportion between groups (higher results in the $\mathrm{N}$-back group) remained. Although interaction effect per se was not statistically significant, post hoc comparisons revealed that only participants in the N-back group increased their OSPAN scores $(p=0.02)$ (Figure 4A). We have also observed a statistically significant post-training growth in syllogisms task results $(p<0.001)$, regardless of the type of intervention (Figure 4B). In the memory SPAN task the baseline assessments were slightly worse $(p=0.08)$ than after the intervention for all 
TABLE 2 | Multilevel anlaysis of the training data (n-back task).

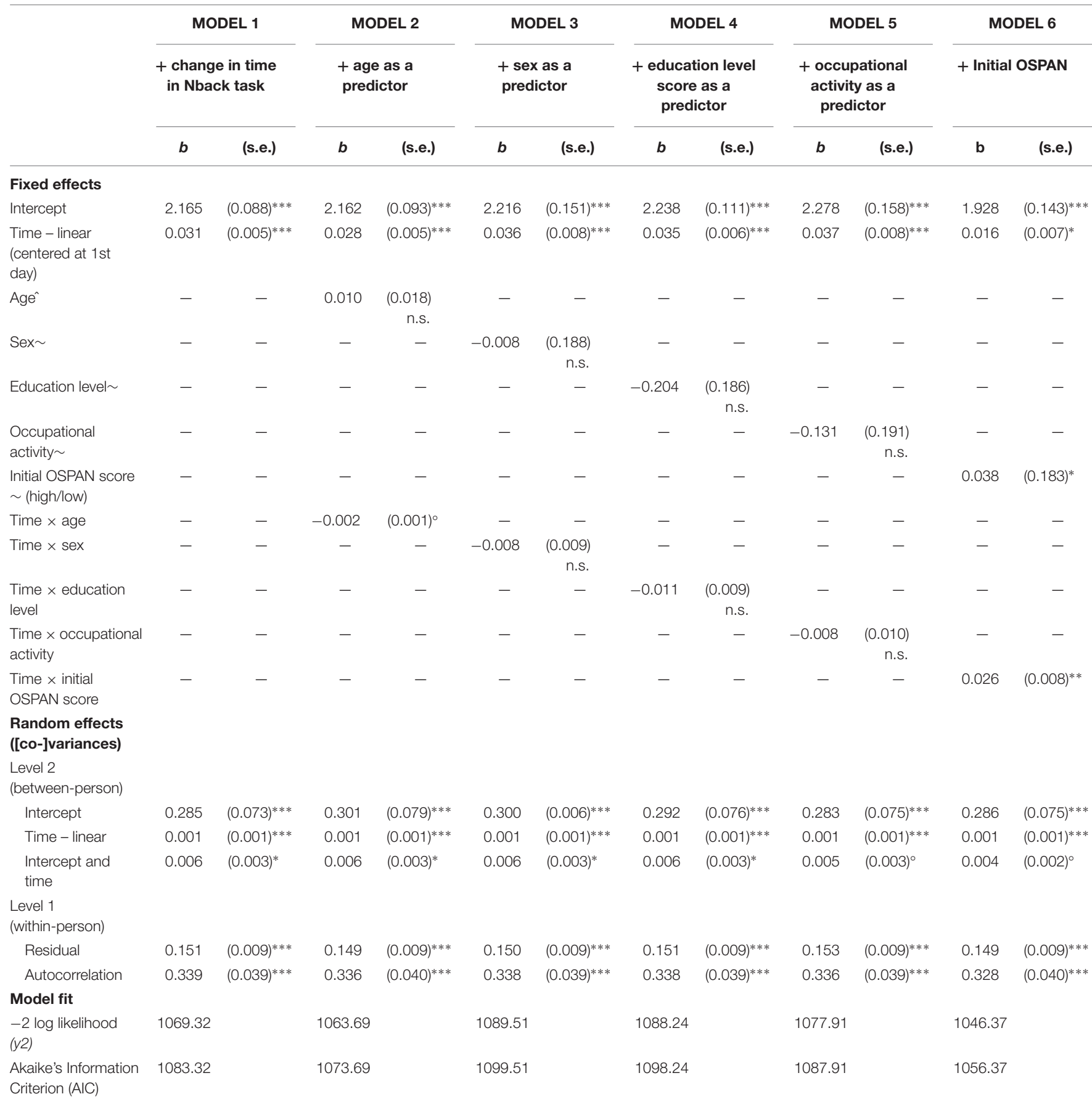

Results from multilevel modeling. Unstandardized regression coefficients listed with standard errors in parenthesis, ${ }^{\circ} p=0.1,{ }^{*} p<0.05,{ }^{* *} p<0.01$, and ${ }^{* * *} p<0.001$. All $p$-Values are two-tailed except in the case of variances, where one-tiled $p$-Values are used (because variances are constrained to be non-negative). ${ }^{\wedge}$ The predictors are mean centered. $\sim$ The predictors are dichotomous.

the participants. However, the analysis showed relatively large disproportion in results between groups: participants in the $\mathrm{N}$-back training group achieved higher scores at baseline, as well as after training (Figure 4C). As could be predicted based on the RM-MANOVA results the post-training scores were also better in both groups in Sternberg's task (a strong tendency toward statistical significance: $p=0.06$ ). Post hoc comparisons revealed that the difference in task accuracy was better after training only in the quiz group $(p=0.06)$ (Figure 4D). Likewise, performance in attention switching increased with time (Figure 4E): switch cost was smaller after the training, which is reflected in the negative difference in means $(p=0.02)$. Pre- and post- training performance in the go/no-go task was dependent on the training group affiliation. Although none of the between-subject effects 


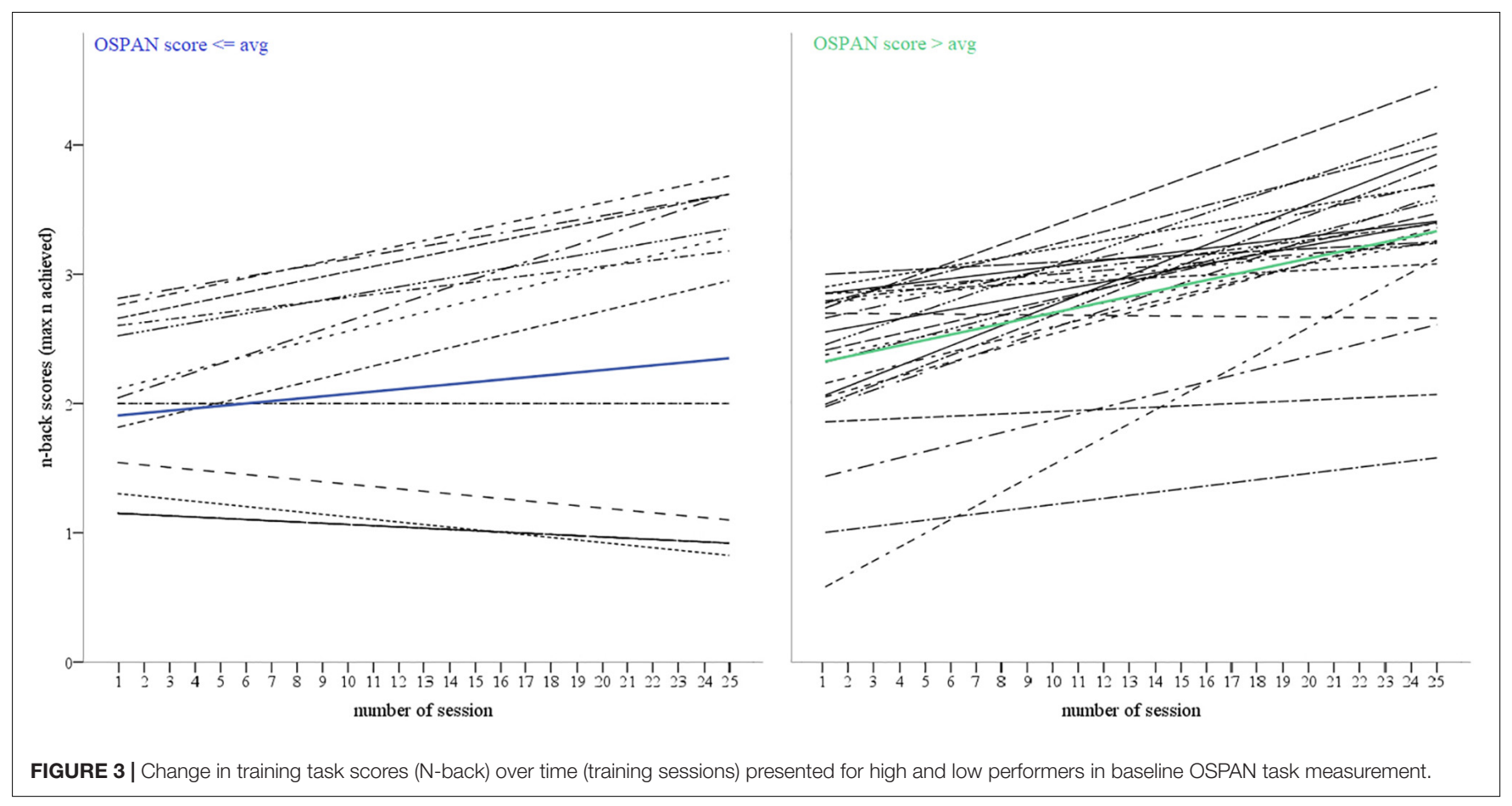

was statistically significant, we found a close to significance interaction $(p=0.09$ ) (Figure $4 \mathbf{F}$ ). Training groups did not differ in the performance on the first measurement, but after the training the participants exercising with the N-back task improved their results (fewer commission mistakes), while the quiz group recorded worse results after the training.

That means that performance in all outcome measures was improved by the intervention. However, only changes in the cognitive inhibition efficiency and WMC appeared to be positive and more pronounced after WM training.

\section{DISCUSSION}

The aim of the study presented here was to investigate the effects of WM training with the dual N-back task in healthy older adults from Poland, developing country with an aging population demography. The first analysis was focused on answering the question of whether there was a progress in the active training task itself. The results showed that most of the elderly participants were able to improve on the N-back task, although we identified a substantial number $(21.4 \%)$ of them not being able to surpass the entering level of $\mathrm{N}$ during the whole training. The specificity of a dual N-back task makes it very challenging, particularly for older adults. Dual N-back simultaneously recruits auditory and visual attention, maintenance, and updating processes. Those are the exact cognitive functions that most commonly decrease with age (Wasylyshyn et al., 2011; Overdorp et al., 2016). At the same time not every senior experience cognitive decline at the same degree (Stern, 2009). There is a possibility that effect observed in physical training of older adults (Godde and Voelcker-Rehage, 2017) is virtual also for cognitive intervention and those, who had started with lower initial level of function trained, finished with a

TABLE 3 | Statistical evaluation of the change in outcome measures.

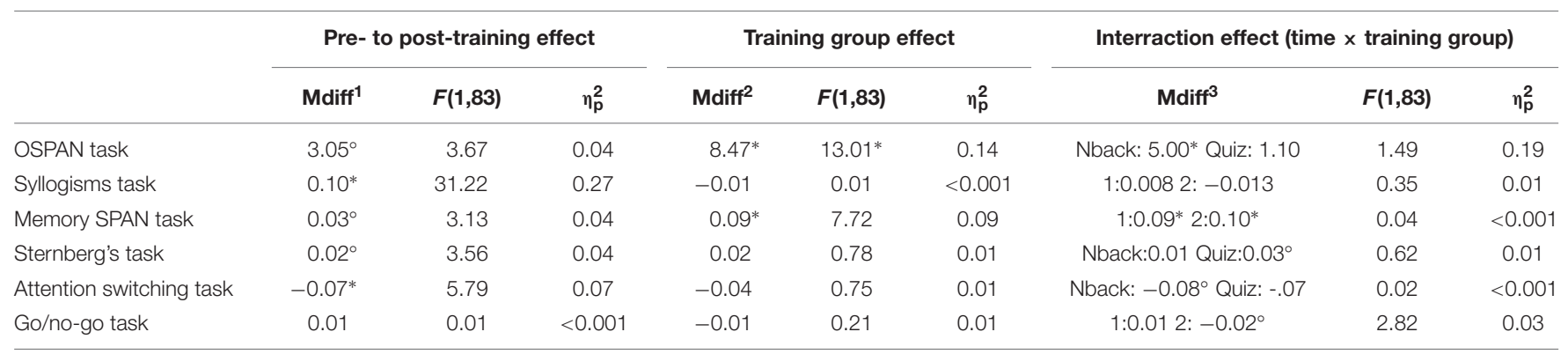

${ }^{1}$ Mean difference (M session 2 - M session 1); ${ }^{2}$ Mean difference: M Nback - M Quiz; ${ }^{3}$ Mean difference for: (a) 1 session: M Nback - M Quiz, 2 session: M Nback - M Quiz (b) Nback: M session 2 - M session 1, Quiz: M session 2 - M session 1. *Statistically significant effect; ${ }^{\circ}$ tendency toward significance 
A

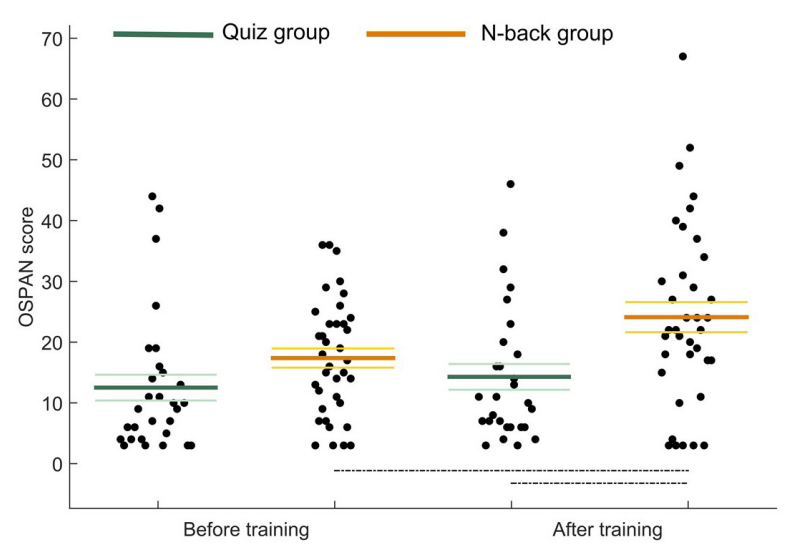

C

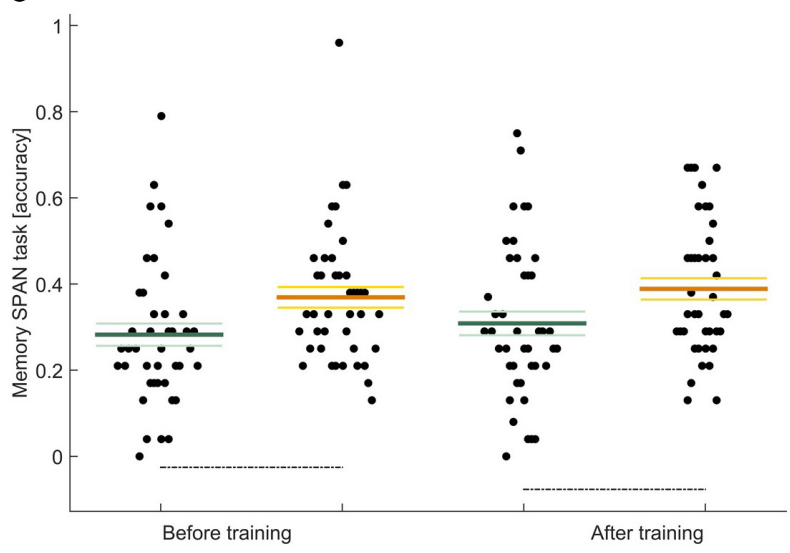

E

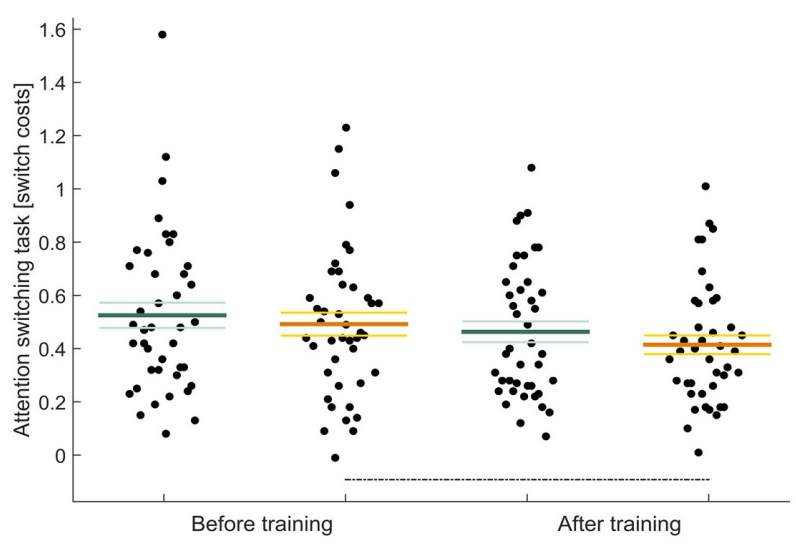

B

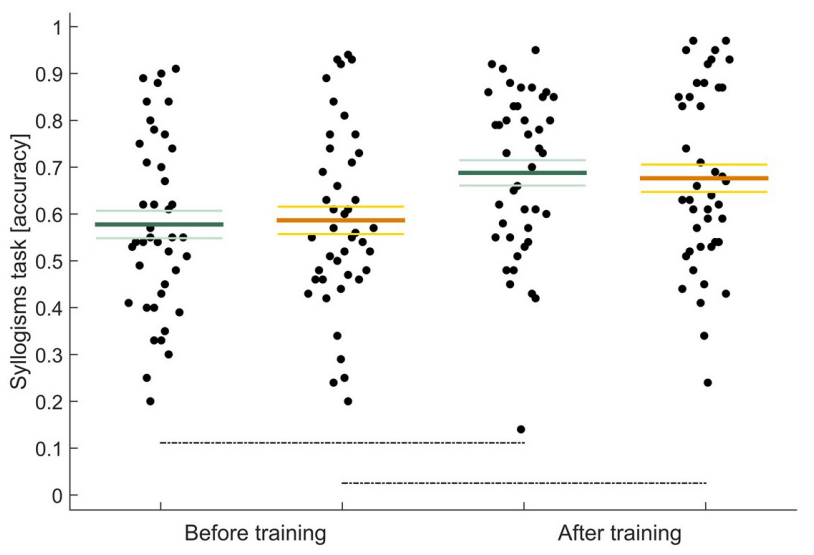

D

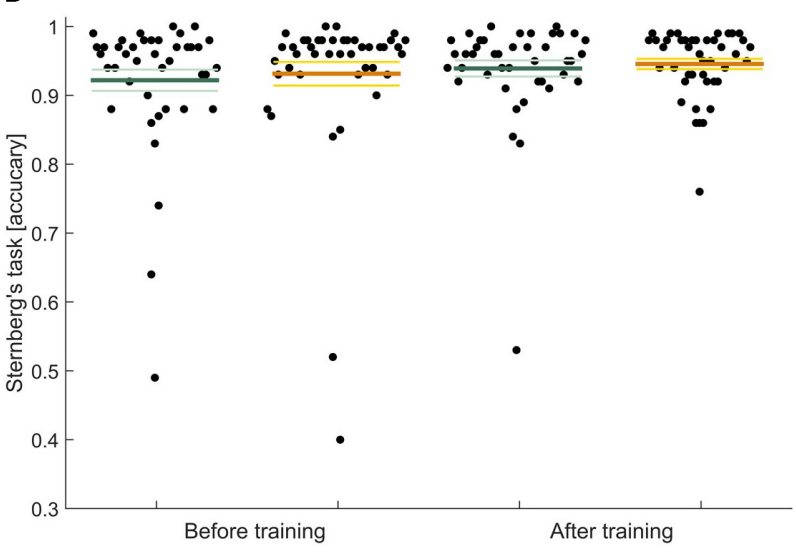

F

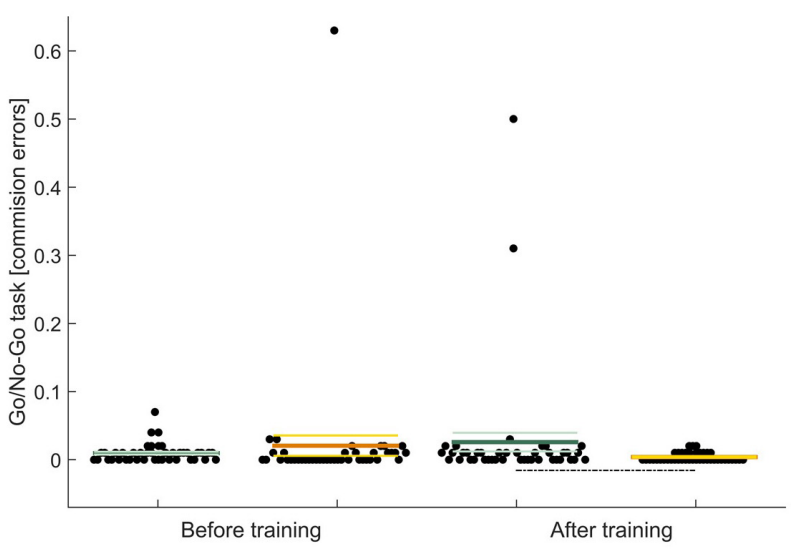

FIGURE 4 | Pre-to-post training changes in measurements of: (A) working capacity - OSPAN task, (B) reasoning - Syllogisms task, (C) working memory span running memory SPAN, (D) short-term memory - Sterberg's task, (E) attention switching - switching task, (F) - cognitive inhibition - go/no-go task.

better post-training results. The multilevel analysis revealed a significant learning effect for the whole group that trained with the N-back task, meaning that, in general, our participants improved throughout the training course. As expected, there was an appreciable variability in the N-back task performance from the early beginning of the training to its end. Individuals with higher maximal $\mathrm{N}$ achieved at the first session improved faster than the others on consecutive training sessions (the effect 
with a high tendency to statistical significance). That indicate that the initial gap in performance between the participants increased with time. A similar result was reported by Foster et al. (2017). They exposed the relation between baseline WM agility and performance on the memory span training tasks, which suggests that a person's ability to gain from WM training depends on this person's prior level of intellectual skills. We explored this matter more closely via another multilevel analysis accommodating initial cognitive discrepancies and demographic variables as predictors of the improvement gained during the training process. The results showed that the preliminary score in OSPAN task, interpreted as a level of cognitive functioning based on the WM capacity assessment (WMC) was a strong predictor of change in the learning curve during the training. Participants characterized by higher initial WMC performed better in training from the very first day and had stepper learning curve in comparison to seniors with WMC below the average of the sample. Those observations are in line with our predictions and studies reporting Matthew effect in WM training interventions, where participants with initial higher ability benefited more from training on this ability as well as on new skills (e.g., Bissig and Lustig, 2007; Borella et al., 2010; Bürki et al., 2014; López-Higes et al., 2018; Kraemer et al., in press).

However, when compared to results supporting contrary hypothesis of compensation effect in cognitive interventions (Mondini et al., 2016; López-Higes et al., 2018) alternative interpretation of our results might be raised. Effects observed in our study could be explained by the mismatch between capacity for plasticity ("supply") and "demands" of the environment, in accordance to the Lövdén et al. (2010) hypothesis. In our study the difficulty of the training task is a demand and one's cognitive abilities are supplies. The discord appears when the demands exceed challenges that the cognitive system usually faces. In those situations individuals might just give up on the task, what could be noticed as a flat learning curve in N-back task. They could also develop task-specific strategies enabling to hurdle task requirements, nonetheless impossible to transfer to performance in post-training measurements. Such strategy should be reflected in worse post-training gains among those subjects. Unfortunately, the size of the sample in our study precludes any reasonable analysis on this matter. Some of the other studies, presenting results contrary to ours, verified posttraining gains using the measure, which was one of our exclusion criterion - MMSE score (López-Higes et al., 2018). It is hence impossible for us to arbitrate how WM training improved the results of participants with low MMSE scores, since they were excluded from the study.

It is important to note that WMC was the only significant predictor of the training progress. None of the demographic variables was a significant predictor of the training effectiveness. This result contrasts with other studies showing that educational achievements (proxy of cognitive reserve) modulate training gains, and participants with lower educational level usually achieve better outcomes (Clark et al., 2016). However, this effect could be also explained by subjects' age. Zinke et al. (2014) examined both initial WMC and age in the context of a WM task performance. They found that both factors - the initial WMC and age - contributed to the amount of a training gain, but age was a weaker predictor than the initial WMC. Thus, age influence on training outcomes probably reflects the sole effect of pre-training cognitive ability rather than a general cognitive decline over the life-span (von Bastian and Oberauer, 2014). It may be that including old-old adults would affect the magnitude of the effect of the age on training gains, because they experience a more noticeable cognitive decline than the young-old (Borella et al., 2007), regrettably our oldest participant was 81 years old. Nevertheless, these observations give foundations for further exploration of an influence of initial variability in cognition on training gains.

Our third analysis concerned the effectiveness of training through its impact on the measures of cognitive functioning. We expected post-training improvement in the tasks involving the same function as the one being trained (Operation SPAN Task, Sternberg's Task, memory SPAN task) and insignificant training effects for tasks distantly related to WM (attention switching, syllogisms, and go/no-go tasks). According to Barnett and Ceci's taxonomy (Barnett and Ceci, 2002) near transfer appears when training task and outcome measures are structurally similar. Executing N-back is likely to lead to improvements on similar in design and structure N-back task, as was demonstrated by Lilienthal et al. (2013) and von Bastian and Eschen (2016). With dual N-back task we were aiming to train a processes of WM, and verify if the process was improved afterward. That is the reason why we used the memory SPAN and OSPAN tasks, which are as far as possible from training task in design, however, they are still measures of the same cognitive construct. Therefore, improvement in those tasks should be seen more as indicator of the mid-transfer rather than near transfer. The third indicator of memory abilities - Sternberg task - is a measure of short-term memory (STM) capacity. That is why training influence on its scores is treated as an evidence of the far transfer. Likewise, a syllogistic reasoning task. As we predicted, analyses revealed significant post-training gains in memory SPAN task accuracy and operation SPAN scores only in an N-back group (near transfer). An opposite effect was found for Sternberg task - only the quiz group showed an improvement after training. With respect to the STM, it should be noted that the $\mathrm{N}$-back task requires temporary storage, and training might increase short-term storage capacity in either the verbal or the spatial domain. Apparently, the discrepancy between verbal/spatial (N-back) and visual (Sternberg's task) stimuli in the tasks obstructed post-training gains or the N-back tasks simply do not promote STM capacity. Such explanation could be supported by the lack of transfer to STM capacity, which was also found in several other studies (e.g., Owen et al., 2010; Lilienthal et al., 2013). To our surprise, the quiz training group showed improvement in this task. Although we did not exclude the possibility of observing positive changes after the semantic memory training, we assumed that they would be rather subtle. However, Kuo et al. (2018) demonstrated that significant posttraining improvement in EF (such as attentional control engaged in simultaneous execution of WM task) could be observed after semantic memory training. 
Further analysis revealed the lack of training effects on inhibitory control tasks in both training groups. The higher post-training results were found in the active control group, but pre-to-post training changes were insignificant in both groups. While interpreting this results, especially when the screened group consists of older adults, it is important to be aware of the conflict at the perceptual and/or motor level. Aging processes may differently affect motor and perceptual inhibition as well as the interplay between them. It is almost impossible to determine which of those two played a greater role in making the errors in go/no-go task when only behavioral measures were taken into account. Unfortunately, we did not control for our participants' motor functions. It is also suggested that the increased noise in perceptual processing is a key factor for age-related memory reductions (Schneider and Pichora-Fuller, 2000). The decrease in sensory functioning may demand a greater cognitive effort to uphold sensory functioning, thus leaving less available resources for cognitive operations. It has been shown that older adults under quiet conditions perform at the same level as if younger adults were presented with information in auditory noise (Murphy et al., 2000). The quiz group, that trained with less cognitively demanding, semantic memory task at home (in a noiseuncontrolled environment) could be less challenged to overcome the influence of surrounding distractors. Therefore, it is possible that they developed different, and possibly less effective strategies eliminating signal-to-noise ratio influence on task performance than N-back group which was exposed to a severe attention load. Related to the inhibitory deficit theory are claims that the amount of attentional resources is the limiting factor in aging. Decades ago studies showed that, under divided attention conditions, younger adults lower their performance to similar levels as older adults under single-task conditions (Anderson et al., 1998). To proceed under these circumstances people need to allocate all attentional resources, and if they are not sufficiently available, the encoding and subsequent recall will be affected negatively. Regarding this, it is unsurprising that a positive posttraining effect in attention switching task was found only in N-back group.

We would like to put the emphasis on the recent reinterpretation of WM interventions reporting positive effects of WM training relative to control groups. It revealed that observed transfer effects were present due to decreases in control group performance rather than reliable increases in training groups (Redick, 2015). That is why it is important to stress that our study showed lack of post-training reduction in outcome

\section{REFERENCES}

Anderson, N., Craik, F., and Naveh-Benjamin, M. (1998). The attentional demands of encoding and retrieval in younger and older adults: I. Evidence from divided attention costs. Psychol. Aging 13, 405-423. doi: 10.1037/0882-7974.13.3.405

Anderson, D. K., Liang, J. W., and Lord, C. (2014). Predicting young adult outcome among more and less cognitively able individuals with autism spectrum disorders. J. Child Psychol. Psychiatry 55, 485-494. doi: 10.1111/jcpp. 12178 measurements in the quiz group, except for the go/no-go task. It is also worth noticing that the social engagement in general is considered to be the main factor in maintaining good intellectual health. We have to remember that all our participants (regardless of group belongingness) volunteered to the study. Correlational studies have shown that voluntary work protects against cognitive aging (reviews: Anderson et al., 2014; Guiney and Machado, 2018; Proulx et al., 2018), so we cannot exclude the possibility that any new and voluntary engagement might be intellectually beneficial for elderly people. Overall, our findings do fit well with the research suggesting that post-training gains are within reach of older adults. However, it is always advisable to achieve the best possible cognitive agility as early as possible and before aging deficits appear.

\section{ETHICS STATEMENT}

This study was carried out in accordance with the recommendations of the SWPS University of Social Sciences and Humanities Ethics Committee with written informed consent from all participants. All participants gave written informed consent in accordance with the Declaration of Helsinki. The protocol was approved by the University Ethics Committee.

\section{AUTHOR CONTRIBUTIONS}

$\mathrm{AB}$ developed the theoretical framework and supervised the project, and corrected the manuscript. OM carried out the experiments and wrote the manuscript. OM and AK performed the analytic calculations. AK corrected the manuscript.

\section{FUNDING}

This material is based upon work supported by the National Science Centre in Poland under grant no. 2014/13/B/HS6/03155.

\section{ACKNOWLEDGMENTS}

We would like to show our gratitude to members of a research team and students who helped in carrying out the study. We are immensely grateful to Maksymilian Osowski for stylistic and linguistic corrections of an earlier version of the manuscript. 
intervention in the home environment. Rev. Educ. Res. 75, 1-26. doi: 10.3102/ 00346543075001001

Baltes, P. B. (1987). Theoretical propositions of life-span developmental psychology: on the dynamics between growth and decline. Dev. Psychol. 23, 611-626. doi: 10.1037/0012-1649.23.5.611

Barnett, S. M., and Ceci, S. J. (2002). When and where do we apply what we learn? a taxonomy for far transfer. Psychol. Bull. 128, 612-637. doi: 10.1037/0033-2909. 128.4.612

Barrouillet, P., and Lecas, J.-F. (1999). Mental models in conditional reasoning and working memory. Think. Reason. 5, 289-302. doi: 10.1080/135467899393940

Bissig, D., and Lustig, C. (2007). Who benefits from memory training? Psychol. Sci. 18, 720-726. doi: 10.1111/j.1467-9280.2007.01966.x

Bleckley, M. K., Durso, F. T., Crutchfield, J. M., Engle, R. W., and Khanna, M. M. (2003). Individual differences in working memory capacity predict visual attention allocation. Psychon. Bull. Rev. 10, 884-889. doi: 10.3758/BF031 96548

Bolger, N., and Laurenceau, J.-P. (2013). "Methodology in the social sciences," Intensive Longitudinal Methods: An Introduction to Diary and Experience Sampling Research. New York, NY: Guilford Press.

Borella, E., Carbone, E., Pastore, M., De Beni, R., and Carretti, B. (2017). Working memory training for healthy older adults: the role of individual characteristics in explaining short- and long-term gains. Front. Hum. Neurosci. 11:99. doi: 10.3389/fnhum.2017.00099

Borella, E., Carretti, B., and De Beni, R. (2007). Working memory and inhibition across the adult life-span. Acta Psychol. 128, 33-44. doi: 10.1016/j.actpsy.2007. 09.008

Borella, E., Carretti, B., Riboldi, F., and De Beni, R. (2010). Working memory training in older adults: evidence of transfer and maintenance effects. Psychol. Aging 25, 767-778. doi: 10.1037/a0020683

Borella, E., and De Ribaupierre, A. (2014). The role of working memory, inhibition, and processing speed in text comprehension in children. Learn. Individ. Diff. 34, 86-92. doi: 10.1016/j.lindif.2014.05.001

Brehmer, Y., Westerberg, H., and Bäckman, L. (2012). Working-memory training in younger and older adults: training gains, transfer, and maintenance. Front. Hum. Neurosci. 6:63. doi: 10.3389/fnhum.2012.00063

Bürki, C. N., Ludwig, C., Chicherio, C., and de Ribaupierre, A. (2014). Individual differences in cognitive plasticity: an investigation of training curves in younger and older adults. Psychol. Res. 78, 821-835. doi: 10.1007/s00426-014-0559-3

Clark, D. O., Xu, H., Unverzagt, F. W., and Hendrie, H. (2016). Does targeted cognitive training reduce educational disparities in cognitive function among cognitively normal older adults? Int. J. Geriatr. Psychiatry 31, 809-817. doi: 10.1002/gps.4395

Colzato, L. S., van den Wildenberg, W. P. M., Zmigrod, S., and Hommel, B. (2013). Action video gaming and cognitive control: playing first person shooter games is associated with improvement in working memory but not action inhibition. Psychol. Res. 77, 234-239. doi: 10.1007/s00426-012-0415-2

Conway, A. R., Cowan, N., Bunting, M. F., Therriault, D. J., and Minkoff, S. R. (2002). A latent variable analysis of working memory capacity, short-term memory capacity, processing speed, and general fluid intelligence. Intelligence 30, 163-183. doi: 10.1016/S0160-2896(01)00096-4

Cowan, N. (2010). ). The magical mystery four. Curr. Dir. Psychol. Sci. 19, 51-57. doi: 10.1177/0963721409359277

Dahlin, E., Neely, A. S., Larsson, A., Backman, L., and Nyberg, L. (2008). Transfer of learning after updating training mediated by the striatum. Science 320 , 1510-1512. doi: 10.1126/science. 1155466

Daneman, M., and Carpenter, P. A. (1980). Individual differences in working memory and reading. J. Verb. Learn. Verb. Behav. 19, 450-466. doi: 10.1016/ S0022-5371(80)90312-6

Dobrowolski, P., Hanusz, K., Sobczyk, B., Skorko, M., and Wiatrow, A. (2015). Cognitive enhancement in video game players: the role of video game genre. Comp. Hum. Behav. 44, 59-63. doi: 10.1016/j.chb.2014.11.051

Dorbath, L., Hasselhorn, M., and Titz, C. (2011). Aging and executive functioning: a training study on focus-switching. Front. Psychol. 2:257. doi: 10.3389/fpsyg. 2011.00257

Dougherty, M. R., Hamovitz, T., and Tidwell, J. W. (2016). Reevaluating the effectiveness of n-back training on transfer through the Bayesian lens: support for the null. Psychon. Bull. Rev. 23, 306-316. doi: 10.3758/s13423-0150865-9
Engle, R. W., Tuholski, S. W., Laughlin, J. E., and Conway, A. R. A. (1999). Working memory, short-term memory, and general fluid intelligence: a latent-variable approach. J. Exp. Psychol. Gen. 128, 309-331. doi: 10.1037/0096-3445.128.3.309

Folstein, M. F., Folstein, S. E., and McHugh, P. R. (1975). \&quot;Mini-mental state\&quot; a practical method for grading the cognitive state of patients for the clinician. J. Psychiatr. Res. 12, 189-198.

Foster, J. L., Harrison, T. L., Hicks, K. L., Draheim, C., Redick, T. S., and Engle, R. W. (2017). Do the effects of working memory training depend on baseline ability level? J. Exp. Psychol. Learn. Mem. Cogn. 43, 1677-1689. doi: 10.1037/ $\mathrm{xlm} 0000426$

Fry, A. F., and Hale, S. (1996). Processing speed, working memory, and fluid intelligence: evidence for a developmental cascade. Psychol. Sci. 7, 237-241. doi: 10.1111/j.1467-9280.1996.tb00366.x

Fukuda, K., and Vogel, E. K. (2009). Human variation in overriding attentional capture. J. Neurosci. 29, 8726-8733. doi: 10.1523/JNEUROSCI.2145-09.2009

Godde, B., and Voelcker-Rehage, C. (2017). Cognitive resources necessary for motor control in older adults are reduced by walking and coordination training. Front. Hum. Neurosci. 11:156. doi: 10.3389/fnhum.2017.00156

Guiney, H., and Machado, L. (2018). Volunteering in the community: potential benefits for cognitive aging. J. Gerontol. Ser. B 73, 399-408. doi: 10.1093/geronb/ gbx134

Harada, C. N., Natelson Love, M. C., and Triebel, K. L. (2013). Normal cognitive aging. Clin. Geriatr. Med. 29, 737-752. doi: 10.1016/j.cger.2013.07.002

Heinzel, S., Schulte, S., Onken, J., Duong, Q.-L., Riemer, T. G., Heinz, A., et al. (2014). Working memory training improvements and gains in non-trained cognitive tasks in young and older adults. Aging Neuropsychol. Cogn. 21, 146-173. doi: 10.1080/13825585.2013.790338

Hertzog, C., Kramer, A. F., Wilson, R. S., and Lindenberger, U. (2008). Enrichment effects on adult cognitive development. Psychol. Sci. Public Interest 9, 1-65. doi: 10.1111/j.1539-6053.2009.01034.x

Huizinga, M., Dolan, C. V., and van der Molen, M. W. (2006). Age-related change in executive function: Developmental trends and a latent variable analysis. Neuropsychologia 44, 2017-2036. doi: 10.1016/j.neuropsychologia.2006.01.010

Jaeggi, S. M., Buschkuehl, M., Jonides, J., and Perrig, W. J. (2008). Improving fluid intelligence with training on working memory. PNAS 105, 6829-6833. doi: 10.1073/pnas.0801268105

Johnson-Laird, P. N. (1983). Mental Models: Towards a Cognitive Science of Language, Inference, and Consciousness. Cambridge, MA: Harvard University Press.

Kane, M. J., Bleckley, M. K., Conway, A. R., and Engle, R. W. (2001). A controlledattention view of working-memory capacity. J. Exp. Psychol. 130, 169-183. doi: 10.1037/0096-3445.130.2.169

Kane, M. J., Brown, L. E., Little, J. C., Silvia, P. J., Myin-Germeys, I., and Kwapil, T. (2007). For whom the mind wanders, and when: an experience-sampling study of working memory and executive control in daily life. Psychol. Sci. 18, 614-621. doi: 10.1111/j.1467-9280.2007.01948.x

Karbach, J., and Verhaeghen, P. (2014). Making working memory work: a metaanalysis of executive-control and working memory training in older adults. Psychol. Sci. 25, 2027-2037. doi: 10.1177/0956797614548725

Klencklen, G., Banta Lavenex, P., Brandner, C., and Lavenex, P. (2017). Working memory decline in normal aging: memory load and representational demands affect performance. Learn. Motiv. 60, 10-22. doi: 10.1016/j.lmot.2017.09.002

Kliegel, M., and Bürki, C. (2012). Memory training interventions require a tailormade approach: commentary on McDaniel and Bugg. J. Appl. Res. Mem. Cogn. 1, 58-60. doi: 10.1016/J.JARMAC.2012.01.002

Kraemer, K. R., Enam, T., and McDonough, I. M. (in press). Cognitive reserve moderates older adults' memory errors in an autobiographical reality monitoring task. Psychol. Neurosci. doi: 10.1037/pne0000161

Kramer, A. F., Hahn, S., and Gopher, D. (1999). Task coordination and aging: explorations of executive control processes in the task switching paradigm. Acta Psychol. 101, 339-378. doi: 10.1016/S0001-6918(99)00011-6

Kuo, C. Y., Huang, Y. M., and Yeh, Y. Y. (2018). Let's play cards: multi-component cognitive training with social engagement enhances executive control in older adults. Front. Psychol. 9:2482. doi: 10.3389/fpsyg.2018.02482

Kwok, O.-M., Underhill, A. T., Berry, J. W., Luo, W., Elliott, T. R., and Yoon, M. (2008). Analyzing longitudinal data with multilevel models: an example with individuals living with lower extremity intra-articular fractures. Rehabil. Psychol. 53, 370-386. doi: 10.1037/a0012765 
Kyllonen, P. C., and Christal, R. E. (1990). Reasoning ability is (little more than) working-memory capacity?! Intelligence 14 , 389-433. doi: 10.1016/S01602896(05)80012-1

Li, B., Zhu, X., Hou, J., Chen, T., Wang, P., and Li, J. (2016). Combined cognitive training vs. memory strategy training in healthy older adults. Front. Psychol. 7:834. doi: 10.3389/fpsyg.2016.00834

Li, S.-C., Schmiedek, F., Huxhold, O., Röcke, C., Smith, J., and Lindenberger, U. (2008). Working memory plasticity in old age: practice gain, transfer, and maintenance. Psychol. Aging 23, 731-742. doi: 10.1037/a0014343

Lilienthal, L., Tamez, E., Shelton, J. T., Myerson, J., and Hale, S. (2013). Dual n-back training increases the capacity of the focus of attention. Psychon. Bull. Rev. 20, 135-141. doi: 10.3758/s13423-012-0335-6

Lindenberger, U. (2014). Human cognitive aging: corriger la fortune? Science 346, 572-578. doi: 10.1126/science. 1254403

Logie, R. H., Horne, M. J., and Pettit, L. D. (2015). "When cognitive performance does not decline across the lifespan," in Working Memory and Ageing, eds R. H. Logie and R. G. Morris (New York, NY: Psychology Press).

López-Higes, R., Martín-Aragoneses, M. T., Rubio-Valdehita, S., Delgado-Losada, M. L., Montejo, P., Montenegro, M., et al. (2018). Efficacy of cognitive training in older adults with and without subjective cognitive decline is associated with inhibition efficiency and working memory span, not with cognitive reserve. Front. Aging Neurosci. 10:23. doi: 10.3389/fnagi.2018. 00023

Lövdén, M., Bäckman, L., Lindenberger, U., Schaefer, S., and Schmiedek, F. (2010). A theoretical framework for the study of adult cognitive plasticity. Psychol. Bull. 136, 659-676. doi: 10.1037/a0020080

Lustig, C., Hasher, L., and Zacks, R. T. (2007). "Inhibitory deficit theory: Recent developments in a \&quot;new view\&quot," in Inhibition in Cognition, eds D. S. Gorfein and C. M. MacLeod (Washington, DC: American Psychological Association), 145-162. doi: 10.1037/11587-008

McCabe, J. A., Redick, T. S., and Engle, R. W. (2016). Brain-training pessimism, but applied-memory optimism. Psychol. Sci. Public Interest 17, 187-191. doi: $10.1177 / 1529100616664716$

Melby-Lervåg, M., and Hulme, C. (2013). Is working memory training effective? A meta-analytic review. Dev. Psychol. 49, 270-291. doi: 10.1037/a0028228

Melby-Lervåg, M., Redick, T. S., and Hulme, C. (2016). Working memory training does not improve performance on measures of intelligence or other measures of "far transfer". Perspect. Psychol. Sci. 11, 512-534. doi: 10.1177/ 1745691616635612

Miyake, A., Friedman, N. P., Emerson, M. J., Witzki, A. H., Howerter, A., and Wager, T. D. (2000). The unity and diversity of executive functions and their contributions to complex "Frontal Lobe" tasks: a latent variable analysis. Cogn. Psychol. 41, 49-100. doi: 10.1006/cogp.1999.0734

Mondini, S., Madella, I., Zangrossi, A., Bigolin, A., Tomasi, C., Michieletto, M., et al. (2016). Cognitive reserve in dementia: implications for cognitive training. Front. Aging Neurosci. 8:84. doi: 10.3389/fnagi.2016.00084

Murphy, D. R., Craik, F. I. M., Li, K. Z. H., and Schneider, B. A. (2000). Comparing the effects of aging and background noise on short-term memory performance. Psychol. Aging 15, 323-334. doi: 10.1037/0882-7974.15.2.323

Nagel, I. E., and Lindenberger, U. (2015). "Adult age differences in working memory: Evidence from functional neuroimaging," in Working Memory and Ageing, eds R. H. Logie and R. G. Morris (New York, NY: Psychology Press).

Office for National Statistics (2017). Past and Projected Data from the Period and Cohort Life Tables, 2016-based, UK: 1981 to 2066.

Olazarán, J., Muñiz, R., Reisberg, B., Peña-Casanova, J., del Ser, T., Cruz-Jentoft, A. J., et al. (2004). Benefits of cognitive-motor intervention in MCI and mild to moderate Alzheimer disease. Neurology 63, 2348-2353. doi: 10.1212/01.WNL. 0000147478.03911 .28

Overdorp, E. J., Kessels, R. P., Claassen, J. A., and Oosterman, J. M. (2016). The combined effect of neuropsychological and neuropathological deficits on instrumental activities of daily living in older adults: a systematic review. Neuropsychol. Rev. 26, 92-106. doi: 10.1007/s11065-015-9312-y

Owen, A. M., Hampshire, A., Grahn, J. A., Stenton, R., Dajani, S., Burns, A. S., et al. (2010). Putting brain training to the test. Nature 465, 775-778. doi: 10.1038/ nature09042

Park, D. C., Lautenschlager, G., Hedden, T., Davidson, N. S., Smith, A. D., and Smith, P. K. (2002). Models of visuospatial and verbal memory across the adult life span. Psychol. Aging 17, 299-320. doi: 10.1037/0882-7974.17.2.299

Park, D. C., and Payer, D. (2006). "Working memory across the adult lifespan," in Lifespan Cognition: Mechanisms of Change, ed. E. Bialystok (Oxford: Oxford
University Press), 128-142. doi: 10.1093/acprof:oso/9780195169539.003. 0009

Piryaei, S., and Ashkzari, M. K. (2017). A meta-analysis of cognitive training on memory functioning in normal elderly adults. Eur. Psychiatry 41:S609. doi: 10.1016/J.EURPSY.2017.01.962

Proulx, C. M., Curl, A. L., and Ermer, A. E. (2018). Longitudinal associations between formal volunteering and cognitive functioning. J. Gerontol. B Psychol. Sci. Soc. Sci. 73, 522-531. doi: 10.1093/geronb/gbx110

Ranganath, C., Flegal, K. E., and Kelly, L. L. (2011). Can cognitive training improve episodic memory? Neuron 72, 688-691. doi: 10.1016/j.neuron.2011.10.022

Redick, T. S. (2015). Working memory training and interpreting interactions in intelligence interventions. Intelligence 50, 14-20. doi: 10.1016/j.intell.2015.01.014

Rey-Mermet, A., and Gade, M. (2018). Inhibition in aging: what is preserved? what declines? a meta-analysis. Psychon. Bull. Rev. 25, 1695-1716. doi: 10.3758/ s13423-017-1384-7

Richmond, L. L., Morrison, A. B., Chein, J. M., and Olson, I. R. (2011). Working memory training and transfer in older adults. Psychol. Aging 26, 813-822. doi: $10.1037 / \mathrm{a} 0023631$

Salthouse, T. A. (2006). Mental exercise and mental aging. Perspect. Psychol. Sci. 1, 68-87. doi: 10.1111/j.1745-6916.2006.00005.x

Salthouse, T. A. (2009). When does age-related cognitive decline begin? Neurobiol. Aging 30, 507-514. doi: 10.1016/j.neurobiolaging.2008.09.023

Schmiedek, F., Lövdén, M., and Lindenberger, U. (2010). Hundred days of cognitive training enhance broad cognitive abilities in adulthood: findings from the cogito study. Front. Aging Neurosci. 2:27. doi: 10.3389/fnagi.2010.00027

Schneider, B. A., and Pichora-Fuller, M. K. (2000). "Implications of perceptual deterioration for cognitive aging research," in The Handbook of Aging and Cognition, eds F. I. M. Craik and T. A. Salthouse (Mahwah, NJ: Lawrence Erlbaum Associates Publishers), 155-219.

Schwaighofer, M., Fischer, F., and Bühner, M. (2015). Does working memory training transfer? a meta-analysis including training conditions as moderators. Educ. Psychol. 50, 138-166. doi: 10.1080/00461520.2015.1036274

Shinaver, C. S., Entwistle, P. C., and Söderqvist, S. (2014). Cogmed WM training: reviewing the reviews. Appl. Neuropsychol. Child 3, 163-172. doi: 10.1080/ 21622965.2013.875314

Shipstead, Z., Redick, T. S., and Engle, R. W. (2010). Does working memory training generalize? Psychol. Belg. 50, 245-276. doi: 10.5334/pb-50-3-4-245

Shipstead, Z., Redick, T. S., and Engle, R. W. (2012). Is working memory training effective? Psychol. Bull. 138, 628-654. doi: 10.1037/a0027473

Soveri, A., Antfolk, J., Karlsson, L., Salo, B., and Laine, M. (2017). Working memory training revisited: A multi-level meta-analysis of n-back training studies. Psychon. Bull. Rev. 24, 1077-1096. doi: 10.3758/s13423-0161217-0

Stern, Y. (2009). Cognitive reserve. Neuropsychologia 47, 2015-2028. doi: 10.1016/ j.neuropsychologia.2009.03.004

Sternberg, S. (1966). High-speed scanning in human memory. Science 153, 652654. doi: $10.1126 /$ science. 153.3736 .652

Thompson, T. W., Waskom, M. L., Garel, K.-L. A., Cardenas-Iniguez, C., Reynolds, G. O., Winter, R., et al. (2013). Failure of working memory training to enhance cognition or intelligence. PLoS One 8:e63614. doi: 10.1371/journal. pone.0063614

Turner, M. L., and Engle, R. W. (1989). Is working memory capacity task dependent? J. Mem. Lang. 28, 127-154. doi: 10.1016/0749-596X(89) 90040-5

Unsworth, N., Heitz, R. P., Schrock, J. C., and Engle, R. W. (2005). An automated version of the operation span task. Behav. Res. Methods 37, 498-505. doi: 10. 3758/BF03192720

Verhaeghen, P., and Marcoen, A. (1996). On the mechanisms of plasticity in young and older adults after instruction in the method of loci: evidence for an amplification model. Psychol. Aging 11, 164-178. doi: 10.1037//0882-7974.11. 1.164

von Bastian, C. C., and Eschen, A. (2016). Does working memory training have to be adaptive? Psychol. Res. 80, 181-194. doi: 10.1007/s00426-0150655-z

von Bastian, C. C., and Oberauer, K. (2014). Effects and mechanisms of working memory training: a review. Psychol. Res. 78, 803-820. doi: 10.1007/s00426-0130524-6

Wahl, H., Schmitt, M., Danner, D., and Coppin, A. (2010). Is the emergence of functional ability decline in early old age related to change in speed of cognitive 
processing and also to change in personality? J. Aging Health 22, 691-712. doi: 10.1177/0898264310372410

Wasylyshyn, C., Verhaeghen, P., and Sliwinski, M. J. (2011). Aging and task switching: a meta-analysis. Psychol. Aging 26, 15-20. doi: 10.1037/a0020912

Weicker, J., Villringer, A., and Thöne-Otto, A. (2016). Can impaired working memory functioning be improved by training? A meta-analysis with a special focus on brain injured patients. Neuropsychology 30, 190-212. doi: 10.1037/ neu0000227

Zając-Lamparska, L., and Trempała, J. (2016). Effects of working memory and attentional control training and their transfer onto fluid intelligence in early and late adulthood. Health Psychol. Rep. 4, 41-53. doi: 10.5114/HPR.2016. 56846

Zinke, K., Einert, M., Pfennig, L., and Kliegel, M. (2012). Plasticity of executive control through task switching training in adolescents. Front. Hum. Neurosci. 6:41. doi: $10.3389 /$ fnhum.2012.00041
Zinke, K., Zeintl, M., Rose, N. S., Putzmann, J., Pydde, A., and Kliegel, M. (2014) Working memory training and transfer in older adults: effects of age, baseline performance, and training gains. Dev. Psychol. 50, 304-315. doi: 10.1037/ a0032982

Conflict of Interest Statement: The authors declare that the research was conducted in the absence of any commercial or financial relationships that could be construed as a potential conflict of interest.

Copyright $\odot 2019$ Matysiak, Kroemeke and Brzezicka. This is an open-access article distributed under the terms of the Creative Commons Attribution License (CC BY).

The use, distribution or reproduction in other forums is permitted, provided the original author(s) and the copyright owner(s) are credited and that the original publication in this journal is cited, in accordance with accepted academic practice. No use, distribution or reproduction is permitted which does not comply with these terms. 